\title{
A Needs Assessment for the Adoption of Next Generation Science Standards (NGSS) in K-12 Education in the United States
}

\author{
Karleah Harris ${ }^{1}$, Alec Sithole ${ }^{2}$, Joachim Kibirige ${ }^{3}$ \\ ${ }^{1}$ Department of Family Science and Social Work, Miami University, 101M McGuffey Hall \\ Oxford, $\mathrm{OH} 45056$ \\ ${ }^{2}$ Department of Computer Science, Mathematics and Physics, Missouri Western State University, 4525 Downs Drive, St. \\ Joseph, MO 64507, USA \\ ${ }^{3}$ Department of Economics, Political Science and Sociology, Missouri Western State University, 4525 Downs Drive, St. \\ Joseph, MO 64507, USA \\ Correspondence: Alec Sithole, Department of Computer Science, Mathematics and Physics, Missouri Western State \\ University, 4525 Downs Drive, St. Joseph, MO 64507, USA.
}

Received: July 2, $2017 \quad$ Accepted: August 1, $2017 \quad$ Online Published: August 3, 2017

doi:10.11114/jets.v5i9.2576 URL: https://doi.org/10.11114/jets.v5i9.2576

\begin{abstract}
Since its inception, the Next Generation Science Standards (NGSS) blue print has attracted interest from more than 40 states in the United States. The overall objective of these proposed changes is to align K-12 science education with current trends in technology and career needs. However, the assessment of teacher preparedness and classroom technology needs is still a critical factor in the implementation of these changes. Our study conducted a needs and preparedness assessment using online surveys on public K-12 teachers before the implementation phase. The data collected for this study comprised 214 responses from schools in 16 states across the US. The study indicates that most of the teachers were not knowledgably equipped to fuse the proposed changes in standards with the current curricula and their teaching plans. The teachers made several suggestions, based on their views regarding the level of preparedness of their students. The implications of these findings and suggestions for further adjustments are presented and discussed.
\end{abstract}

Keywords: public K-12 science education, Next Generation Science Standards (NGSS), teacher preparedness, classroom technology

\section{Introduction}

Assessment scores of K-12 tests administered by the US National Assessment of Educational Progress (NAEP) and the Trends in International Mathematics and Science Study (TIMSS) show that proficiency in science remains low among US students (Gonzales et al., 2008). A recent Nation's Report Card from the National Assessment of Educational Progress (NAEP) showed that the respective proficiency rates for the 4th, 8th and 12 th grades stood at $40 \%, 33 \%$, and $25 \%$ in Mathematics, while in science the proficiency rate was 38\%, 34\%, and 22\% for the same grades (U.S. Department of Education, 2015). Among 71 countries that participated in the Program for International Student Assessment (PISA) in 2015, the U.S. ranked 38th and 24th in mathematics and science, respectively (Kastberg, Chan \& Murray, 2016). In addition, the Council on Foreign Relations (CFR)'s sponsored Independent Task Force Report of 2009 on U.S. Education Reform and National Security found that the percentage of students who fail to graduate from high school within four years was more than $25 \%$ (Klein et al., 2012). In the same report, ACT scores of not-for-profit high school students indicated that their readiness in core subjects was $22 \%$. According to the National Academies of Sciences, Engineering, and Medicine (2015) "many American students and adults still fail to grasp fundamental scientific concepts and to understand the process of scientific discovery" (p. 11). In addition, emerging trends point to a technology-based education in the future. As such, blended learning, online-learning, and technology-driven laboratory activities are already in use in many schools.

However, a major difference is that while countries with high performing science students in TIMSS have progressive/step-wise science curricula, the US science standards are too broad even at lower grade levels (Schmidt et 
al. 2005). Therefore, there is increasing need to develop new methods of teaching and learning to better prepare students for future technology-dependent careers. Deficiencies in K-12 science education have drawn public attention and various players have started to focus on developing viable science education standards (Moreno, 1999). One of the major steps towards this goal was the introduction of the Next Generation Science Standards (NGSS). According to the National Research Council (2014), the NGSS were intended to transform public K-12 science education so that it provides students with the proper skills and knowledge needed for college and career readiness. As such, the emphasis of these standards is directed toward: i) integration of scientific and engineering practices to develop multiple learning core concepts; ii) sequential progression of knowledge at each grade level; iii) identifying assessible core concepts useful to develop deeper understanding and application of content; and iv) incorporating engineering design into science education with emphasis on developing students' understanding of core concepts in engineering design and technology applications (NGSS Lead States, 2013). This approach in which engineering, technology, and applications of science are integrated and introduced at every grade level of science education is a major shift from the current approach that requires a different kind of thinking and planning by educators. Thus, as more states race to adopt these standards, there is increasing concern about, on the one hand, the readiness of teachers, students, school administrators and staff and, on the other, the availability of needed classroom technology resources to support the implementation of these new standards.

\section{Background}

The National Science Teachers Association (2016) showed that 18 states as well as the District of Columbia have already adapted the NGSS. The eighteen states are "Arkansas, California, Connecticut, Delaware, Hawaii, Illinois, Iowa, Kansas, Kentucky, Maryland, Michigan, Nevada, New Hampshire, New Jersey, Oregon, Rhode Island, Vermont and Washington" (p.1). According to the Next Generation Science Standards Lead States (NGSS Lead States, 2013) there is need to develop science standards which will stimulate and build students' interest in the science, technology, engineering, and mathematics (STEM) fields. Thus, the K-12 STEM fields in the United States need to be strengthened, and NGSS Lead States (2013) described the K-12 STEM field talent pipeline as impermeable because not many students are entering the field. One of the approaches towards this goal is to implement Next Generation Science Standards (NGSS).

Regarding students' interest in STEM subjects, Chen and Soldner (2003) noted: "producing sufficient numbers of graduates who are prepared for science, technology, engineering, and mathematics (STEM) occupations has become a national priority in the United States" (p.iii). Their study showed that students left the STEM fields for various reasons. These included students changing their majors or failing to complete their certification or degree and, consequently, leaving college. Wang and Degol, (2013) explained that math-related careers are connected to youth interest based on how many courses they take in science and math at the high school level. They also observed that "when STEM-related structural features of the school, instructional techniques, and/or teacher-student relationships are lower in quality, females may be more susceptible than their male counterparts to disengage from math and science classes" (p.315). The researchers noted that gender differences and negative stereotypes about math ability may be associated with parental behaviors and interest, beliefs and value regarding STEM. Stout, Grunberg, and Ito, (2016) examined gender and stereotype in physical science, technology, engineering, and mathematics (pSTEM) fields and found that more men tend to follow careers in (pSTEM) fields than women. Steingberg (2011) explained the stereotypes and attitudes that have been linked to STEM fields and further noted that efforts must be made to link perceptions with the reality of STEM during recruitment. There has been a considerable amount of literature conducted on technology in K-12 classrooms (Doering, Koseoglu, Scharber, Henrickson, \& Lanegran, 2014; Lee, Messom, 2013; Liu, Navarrete, \& Wivagg, 2014; Roberts-Mahoney, Means, \& Garrison, 2016). According to Selwyn (2015) "an obvious first step would be the sustained promotion of alternate language for educational technology - encouraging a counter-lexicon that reflects more accurately the conflicts, compromises and exclusions at play" (p.5). Liu, Navarrete, and Wivagg (2014) noted that there has been an increased interest in the use of mobile technology in K-12 classrooms. Several curriculum developers and textbook companies have been designing digital resources to make them available for both teachers and students. Schools are using several different platforms/ LMS integrations (Canvas, Niihka, Blackboard, and Brightspace/D2L) and interactive tools. Companies are building partnerships with institutions and educators. Students and educators are using different technologies in their classrooms such as LaunchPad, Revel, Mindtap, Connect, Clickers, REEF polling, and other mobile technologies. According to Wysession (2015) "the digital format also allows for better integration of formative assessments within curricular modules" (p. 1174). Therefore, using technology in K-12 science education is very important and should not be over looked.

\subsection{Statement of the Problem}

Next Generation Science Standards (NGSS) is central to the field of Science. The standards consist of three dimensions: practices, disciplinary core ideas, and crosscutting concepts which are incorporated in the K-12 science education 
framework (NGSS: NGSS Lead States, 2013). Science is very important in our lives and having a good K-12 science education can help students in many ways; for example, if students choose to work in hospitals as technicians, researchers, or in high-tech manufacturing facilities. It is, therefore, crucial to continue to create future jobs, and to invest in scientific innovation (NGSS: NGSS Lead States, 2013). The National Science Teachers Association (2016) described the importance of adopting and implementing the NGSS and the benefits of having a high-quality science education for students. Wysession (2015) explained that by implementing the NGSS, students would be more prepared for the careers in the energy industries and they would gain skills and understanding. According to the National Research Council (2012) "Science, engineering, and technology permeate nearly every facet of modern life, and they also hold the key to meeting many of humanity's most pressing current and future challenges" (p.1). The Council also noted that in these fields many people are lacking the fundamental understanding and only a limited number of workers in the United States have a strong background. Thus, the lack of proficiency in science a math (noted earlier in this paper) translates into real-life consequences.

Several researches have been employed in the study of NGSS (Boesdorfer, \& Staude, 2016; Hoeg \& Bencze, 2017; Huff, 2016; Isabelle, 2017; Penuel, Harris, \& DeBarger, 2015). A study on elementary school teachers highlighted the need for teachers to engage students in making observations, explanations, predictions, compare when sorting object and engage in experiments which require using spatial thinking skills (Isabelle, 2017). Huff (2016) noted that coordinating changes can be challenging but not necessarily impossible. In addition, McComas and Nouri (2016) suggested that since the final document of NGSS was released, "state representatives have been debating, accepting, modifying, and even rejecting some of the recommendations of NGSS" (p.560). The studies above provided useful information on NGSS and technology but they did not focus specifically on assessing the concerns, preparedness, and resource availability that affect the use of modern technology in K-12 science education classrooms.

\section{Methods and Materials}

\subsection{Data and Inclusion/Exclusion Criteria}

The data in this study were collected from 16 states in the US using an online questionnaire over a period of three months. The teachers received an email with the survey link. 214 responses were collected from K-12 teachers from the following states: Ohio, Arizona, Arkansas, Georgia, Illinois, California, Delaware, Tennessee, Washington, Vermont, New Jersey, Iowa, Kansas, Kentucky, New York, and Montana. Given that the NGSSs are being implemented by states in public K-12 schools, this study only collected data from public schools in these states. Survey requests and link to the online questionnaire were directed to school administrators.

\subsection{Research Questions}

The success of NGSS in K-12 education reform mostly depends on the teacher's ability to translate the standards into practical lesson plans and classroom activities coupled with the development of sound pedagogical skills. The survey questions used in this study were aimed at identifying teachers' concerns, preparedness, and their suggestions on how the NGSS could be imbedded into their class. A survey questionnaire comprised the following questions: 1) How long have you been teaching? 2) At what level(s) have you taught? 3) What subject(s) do you teach or have you taught? 4) Are you familiar with NGSS standards? If yes, do you think they are achievable goals? 5) What approaches would you suggest to best achieve these goals? 6) How would you rate your knowledge of educational technology? 7) What kind of classroom technology is available and which do you use? 8) How well are the students prepared to use technology-based learning? 9) What problems are they likely to face? 10) Do you think that the NGSS goals are useful or relevant to improving students' understanding of science and enhancing motivation?

\subsection{Data Analysis/Procedures}

Four principal issues were investigated in this study: understanding the length of teaching service and areas of expertise; teachers' knowledge of NGSSs and their preparedness to implement them; teachers' assessment/views on their students' ability to adapt to changes in curricula and advanced technology applications in their learning; and teachers' assessments of the practicality of the expected outcomes. Thus, the data from the survey were divided into four categories based on the questions on the questionnaire: a) demographic data (Questions 1-3); b) Teacher familiarity and preparedness to embrace NGSS in their lesson plans (Questions 4-7); c) Teachers' views on students' preparedness for technology-based learning (Question 8); and d) Achievability of NGSS expectations outcomes (Questions 9-10).

\section{Results}

\subsection{Demographic Data}

The sample data collected from the 214 teachers showed that $12.6 \%, 17.3 \%$, and $70.1 \%$ of teachers had less than 5,5 to 10 , and more than 10 years of teaching service, respectively. Figure 1 presents the proportion of the respondents teaching at each grade level. 


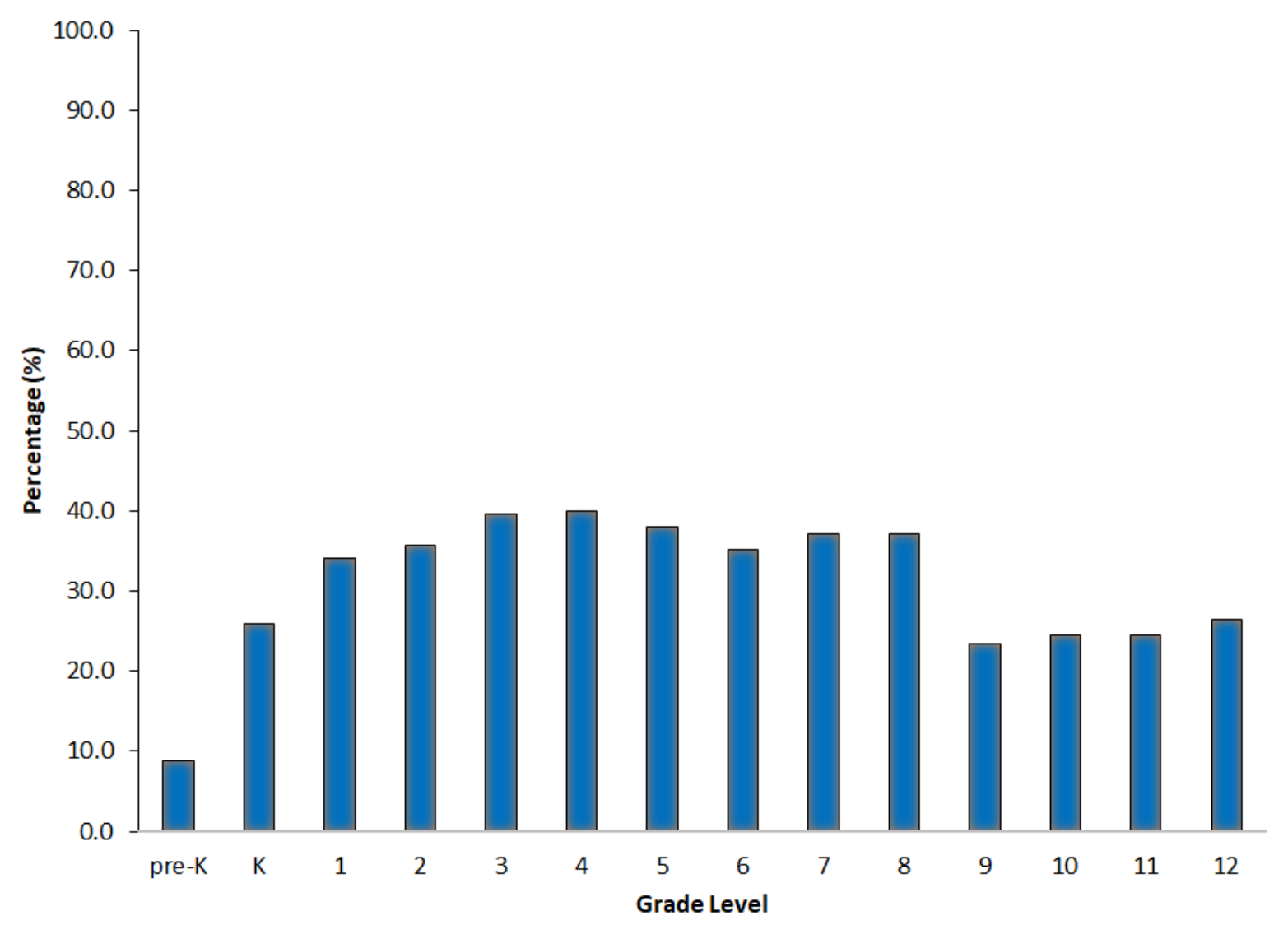

Figure 1. Percentages of the number of respondents per grade level $(\mathrm{N}=214)$.

\subsection{Familiarity and Preparedness}

Of those who responded, $79.4 \%$ had taught either mathematics or science (natural and life sciences) subjects. In addition, about $50 \%$ of the participants indicated familiarity with NGSS standards. While $82.6 \%$ of the respondents thought the goals were achievable, some major concerns were raised and these were: i) viability/practicality - some of the goals were considered difficult to achieve; ii) time constraint - implementing these goals would require substantial time. Some of the goals would make it almost impossible to cover class material adequately in a school year; iii) lack of communication - half the number of teachers had no idea on how the goals could be incorporated into their curricula. Consequently, the scope and sequence needed to ensure the smooth flow of content was needed; iv) inadequate student preparation - the success of these goals was mostly dependent on the ability level of the students and their background preparation. Currently most students struggle with reading and communication; v) inadequacy of resources -currently, not every teacher or school is well-quipped to implement those goals. The same concerns apply to the designing of lessons and to the assessments tools; and vi) teacher training- no formal training on the implementation phase that would help to close the gap in learning between the current and proposed standards in some states.

\subsection{Teachers' Views on Students' Preparedness for Technology-based Learning}

Most teachers believed that embracing technology-based instruction was likely to be impeded by lack, or insufficiency, of technology tools to allow every student to have adequate access. In addition, there is need for more investment in the teacher. As one teacher put it: "My fear is that the current trend seems to be going away from teacher-led classrooms, in the traditional sense. I don't think you can ever replace the effective teacher. Also, with such an increasing dependence on technology, I wonder what will become of our social interactions." In addition, another challenge likely to be experienced was that teachers were likely to struggle to convince students to use technology appropriately to their learning process than to their personal lives. They easily get distracted by the freedom technology affords. In fact, they sometimes have difficulty discerning what is appropriate use for education purposes vs. personal use of technology. For example, students use "text language" for a formal paper. In addition, "students with special needs often face fine motor challenges with using a mouse. They often want to swipe the screen instead of using a mouse. They also get distracted using a computer and think it's time to play games." Also, the current rate at which technology is changing makes it difficult to frequently learn using modern technology. 
While some teachers thought that students generally have excellent understanding of the technical usage of devices, most of their students struggle to use the various kinds of educational tools, such as keyboarding. "Students prefer to use their phones and as a result, aren't as familiar with computer functions as they should be". Most teachers agreed that "Students are very savvy with mobile technology, not so much with basic computing and productivity tools. Some accessibility problems. Very little troubleshooting ability." That means that a lot of time is spent on addressing technical issues since most students may not have computers or iPads at home, thus the need for much practice to learn. The availability of so many resources online makes it difficult for students to identify valid information, which makes it a challenge for teachers to keep them on appropriate websites. In addition, in some science and mathematics courses, "sometimes the technology is a distraction", for example "in math there is nowhere to show their work" which increases a tendency for a student "just to choose an answer when showing their work is not required". Another issue is that in lower grades some students "struggle to use technology independently due to developmental levels and reading abilities." At these levels, some teachers believed "students lack the necessary prerequisites such as reading, writing, listening, or higher-level thinking skills first to then apply to technology."

On the other hand, teachers and students in well-equipped schools thought that the continuing use of technology "would help to engage students in learning better than listening to explanations", and that their use of "apps" and gaming abilities could be a good starting point to teach them to embrace technology in classroom learning. It requires training of both students and teachers to use any technology effectively to avoid wasting of time and distraction from the subject content. The use of whole group demonstration style technology is helpful. In addition, other teachers thought the implementation of NGSS standards was more likely to be stalled by lack of funding to get the devices needed to implement the technology than by student ability. In this case, students from low income families were likely to face more problems than those from affluent homes or districts that have the resources to keep up with technology. Some teachers suggested the use of advanced technology starting at Pre-K level to "bring relevant information to their [learning] experience". However, the current emphasis on STEM education has left some teachers with a feeling that there is too much emphasis on Math and ELA (English Language Arts) assessments while other subjects are left behind. The major concern is that NGSS are being introduced at the same time when the scale is tipped towards ELA.

\subsection{Attainability of NGSS Outcomes}

When teachers were asked about their views regarding the impact of NGSS on improving students' understanding of science and enhancing motivation, there was some general agreement for the need to make improvements in the way science is taught. The implementation of these standards was likely to improve student engagement in the science classroom and to increase their interest in science. An added advantage noted by one respondent was that since "the standards are internationally benchmarked with countries where students score well in science and math", they are likely to enhance student success. Some key issues cited were the "nightmare" of fitting these new standards into the existing curricula and lack of knowledge among the teachers on the planning and direction. One teacher noted: "I think that we are a bit overwhelmed with standards, rules, paperwork, meetings. Even when we see a different direction that we should go in, we don't ever get enough time to develop it into applicable teaching for our students." There is a high likelihood "that "students will miss learning key content and scientific concepts under the inquiry-based model. Also, this model seems more successful with students from a higher socioeconomic group who have more on level reading skills and more background knowledge." Another key issue to the success of this program is the integration of all the "prerequisites that teachers need too to provide students with truly meaningful learning opportunities otherwise, the NGSS are just more things on the plates of teachers who are already so overwhelmed, lacking resources, time, and respect. These will just seem like more requirements like the CCSS [Common Core State Standards] to teachers. We can't plant more seeds until we pull a lot of weeds." Another suggestion was to break down and implement NGSS in steps to allow science teachers and state science testing programs to make the necessary adjustments. There is also need to involve students and parents/guardians in order to build a collective roadmap to success. In addition, the goals must be "aligned by grade level with relative applications outside the classroom." One respondent noted that the "NGSS goals help students understand how science/technology is relevant to them, how it is used in the world around them and how they are learning science by interacting in that world around them." Their focus on the process of science helps students to gain the correct scientific mindset needed to succeed in their careers rather than just gaining a certain set of facts.

\section{Discussion}

This study expands the literature on critical concerns regarding the nature and applicability of NGSS. Based on our findings, the common picture that emerges is that while NGSS goals are appreciated, their implementation is still very problematic. Penuel, et al (2016) mentioned that implementing the NGSS could be challenging since aligning the framework's vision to curriculum materials may be difficult in the-schools that do not have access to the necessary resources, especially in low-income and predominantly minority schools. There are many practical barriers both known 
and unknown that need to be addressed before applying the NGSS program en masse. In other words, we know what we want and it is good but much needs to be done before we are ready. To use an analogy, it is very crucial for the people to keep up with technological change, for example in transportation. If we are switching from transportation by horses to transportation by motor vehicles, we cannot just focus on how to manufacture cars and selling them to people but we must look in advance far and beyond the car itself. There are major pre-requisites before transportation by car can be a reality. For example, we must have proper infrastructure in place, sources of fuel, etc. Cars grow old and need to be repaired or replaced. We must have the resources, both human (engineers, etc.) and material (car parts, etc.) for such replacements. Cars need trained drivers. Even passengers need training. They must be sensitized to the benefits of the new form of transportation without, at the same time, becoming completely dependent on cars alone for every form of mobility. Over dependency on cars can lead to "trained incapacity", where individuals can barely learn to do anything without a car. The population must also be educated about the dangers of cars and the safety measures required. The purpose of the car must also be clearly understood. Cars can be fun but they are not toys. We must also be aware that while cars are beneficial to the entire society, not all people are predisposed to afford a car. Yet, some people can afford multiple cars with all sorts of luxuries. How do we handle these in-built societal inequities in availability, affordability and accessibility of cars?

The gist of the above analogy is that if NGSS is taken as an abstract ideal concept, it represents a lot of what is needed to prepare students for next generation technology. The difference, however is that we can't simply dive into the "next" generation; we can only transition into it. This, therefore, requires prior preparations that can meet and sustain the needs of the general population, without simply amplifying existing structures.

Our study suggests that there is a high level of enthusiasm and support for NGSS objectives both in those schools (or states) that have and those that have not implemented NGSS technology/standards. Penuel, Harris, and DeBarger (2015) observed that the science education community has shown excitement and energy for the NGSS and across the county science leaders are embracing the framework vision even if their states have not adopted NGSS. Based on the findings from our study, however, most of the responses showed a lot of concerns about the practical problems involved in the implementation. This discordance is not necessarily surprising but it is a very crucial factor to consider before applying NGSS extensively. For example, consonant with this finding, the National Science Teachers Association (2016) noted that in order to achieve the NGSS goals, major changes will be required in curriculum, instructions, assessment, professional development, teacher preparation as well as public and administrative support. Boesdorfer and Staude (2016) also mentioned that teachers will not be able to do it alone but are likely to engage in dialogue in their classroom when policy makers and administrators are involved in the discussion. In an ideal situation, NGSS is a noble and very attractive idea, given the trends in the technological developments and trends in all aspects of life, both locally and globally. As society becomes more and more technology-dependent, school is one central place to prepare the future generations to cope with these inevitable changes. Yet, it is very crucial to ensure that the necessary resources are available and that there is the necessary preparedness to sustain the programs, especially since this is a long-term shift in educational pedagogy and philosophy. It, therefore, involves long-term changes many of which will require major structural changes and financial commitments.

Unfortunately, like many other aspects of public life, the social, economic, and even ideological differences present at the wider societal level tend to emerge at every level of any public action or policy. The inequities embedded in the economic arena and the historically precipitated ethnic, and gender inequalities will also have to be put into account if we are to streamline the preparedness of the future generations. It is, however, unrealistic to expect all people to be able to adjust equally to the changes, all of which require resources, including human resources. However, if there is any place where we can streamline such preparedness, there is no better place than K-12 institutions. This is where the seeds of the future are sowed. Such changes, therefore, must be realistic to the kind of future society we may be preparing. Given the wider implications of NGSS, we need to look at the program not in isolation but in its totality in terms of how it relates to the existing dynamics of society and to use the modern technology not to perpetuate existing inequities but to use it as a tool for bringing about equity in education. The key question, however, is how is that goal to be achieved? By simply "diving" into this program, we run the risk of pouring "new wine into old pots". Moreover, experience in other sectors of life shows that without careful preparation and caution, technology can amplify existing inequities by making it very easy for those who can afford it and pushing those who cannot even further down the rungs.

\section{Conclusion and Recommendations}

Findings from our study highlight the lack of knowledge, and a lot of concern, among most teachers on how the NGSS can be integrated in K-12 education system. Teachers grappled with several challenges: changing the current curricula to accommodate NGSS objectives; viability of the program, particularly in poorly resourced schools; and how to set the timelines to complete their syllabi successfully. Many teachers thought that the standards were continuously changing such that they have little time or room to make the necessary adjustments. On the other hand, teachers in well-resourced schools thought that the proposed standards are practically implementable. These variegated views indicate the need to 
address several concerns if these proposed changes are to have a positive effect on student learning outcomes. There is need to close knowledge gaps between K-12 education policy makers and teachers in the field. There are several platforms that can be used to achieve this goal; teacher professional development - this can be implemented through workshops, seminars, conferences, school website online platforms such as webinars, blogs, discussions forums, etc. Alternatively, professional development can take the form of credit online courses for teachers. Penuel et al., (2015) explained that professional development should be student oriented, sustained over time, and linked to classroom teaching. They also indicated that implementing the NGSS "will be easier if we think of teachers and leaders as co-learners instead of demanding compliance to specific indicators of standards that few people understand well" (p.49). The importance of professional development on NGSS is widely recognized and discussed in detail elsewhere (Boesdorfer \& Staude, 2016). Therefore, it is important to provide support and novel approaches for teachers. Providing professional development for teachers is essential and several studies have proved so (Colwell et. al., 2014; Haag \& Megowan, 2015: Micheal, et al., 2016; Tondeur, et al., 2016; Sibert, \& Rieg, 2016). However, identifying, the right professional development is critical. Haag and Megowan, (2015) noted the urgency for identifying professional development, conducting the required research, and realigning professional development resources with the demands that teachers will encounter in the NGSS classrooms. However, Jo Ellen et al., (2017) argued that while professional development could help the teachers, it can also be an unrealistic solution in meeting teachers' needs across science fields and all grade levels by itself. It must be noted, however, that the success in the implementation of these programs depends on the level of financial support either from the schools or the state.

Teachers also shared the belief that technology has taken over a huge part of their classroom activities and affects the way they teach. The study has also shown the discrepancy in the level of preparedness at different schools. While most students could use technology in social networks, their understanding of the basic technology needed in their education was mostly below expectation. As noted by the teachers, technology-driven education requires pre-requisite courses for success and to ensure that more time is dedicated to learning the subject content than technology use. Such adjustments require major changes to lesson plans and the curricula, all of which could have some financial implications. Overall, the study indicates that a significant number of teachers and schools are not well equipped to adopt the NGSS. There is a need to make further assessment on resource needs at every K-12 school in states where these standards are being implemented. These include human resources, capital, pertinent technology, etc.

Finally, we note that the underlying general aim of this research was to assess whether the NGSS program can suitably be applied to all schools at all levels. Consequently, the questions in our survey were selected to reflect as much variety as possible both in terms of the population of teachers as well as the schools. Some of the parameters considered, for example, included length of teaching; subjects taught; availability of technology in the classroom; experiences with technology by teachers; views of teachers concerning the preparedness of their students; and other pertinent parameters as explicated in the discussion. These issues are important in a variety of other ways. For example, the length of teaching also indirectly reflects the variety in age categories which may affect both the attitude and experience with technology. Experience with technology in itself might also reflect the generational diversity of the teachers. On the other hand, availability of technology to some extent gives a glimpse into the socio-economic status of the schools.

Finally, while the sample of 214 respondents may be a modest one, it is clearly a good representation of the general teacher and school population, nationwide. In addition, this was a cross-sectional survey. However, the questions on length of teaching give us a sense of the nature of the trends in both attitudes and preparedness over time. The concerns expressed in the responses to our questions very closely coincide with those reflected in the literature. Likewise, just as is reflected in the literature, it was found that those schools that were better equipped also showed a more sympathetic approach to NGSS while the poorer schools expressed more concerns. We, therefore, conclude that our findings tally with the general situation prevailing in schools nationwide and are a justifiable basis for our recommendations. The hope is that more attention will be paid to these issues at every level before uncritically applying NGSS. In addition, future research is recommended to compare the performance of students in those schools that have adopted the NGSS with those which have not. This will provide information about the effectiveness of NGSS. Such a comparison at this point would be premature since not enough time has elapsed to allow the differences (if any) to be palpable.

\section{References}

Boesdorfer, S. B., \& Staude, K. D. (2016). Teachers' practices in high school chemistry just prior to the adoption of the Next Generation Science Standards. School Science \& Mathematics, 116(8), 442-458. https://doi.org/10.1111/ssm.12199

Chen, X., \& Soldner, M. (2013). STEM attrition: College students' paths into and out of STEM fields statistical analysis report. Washington DC. Retrieved from https://nces.ed.gov/pubs2014/2014001 rev.pdf

Colwell, C., MacIsaac, D., Tichenor, M., Heins, B., \& Piechura, K. (2014). District and university perspectives on 
sustaining professional development schools: Do the NCATE standards matter? Professional Educator, 38(2), $17-26$.

Doering, A., Koseoglu, S., Scharber, C., Henrickson, J., \& Lanegran, D. (2014). Technology integration in K-12 geography education using TPACK as a conceptual model Journal of Geography, 113, 223-237. https://doi.org/10.1080/00221341.2014.896393

Gonzales, P., Williams, T., Jocelyn, L., Roey, S., Kastberg, D., \& Brenwald, S. (2008). Highlights from TIMSS 2007: mathematics and science achievement of U.S. fourth-and eighth-grade students in an international context (NCES 2009-001 Revised). National Center for Education Statistics, Institute of Education Sciences, U.S. Department of Education. Washington, DC.

Haag, S., \& Megowan, C. (2015). Next generation science standards: A national mixed-methods study on teacher readiness. School Science \& Mathematics, 115(8), 416-426. https://doi.org/10.1111/ssm.12145

Hoeg, D. G., \& Bencze, J. L. (2017). Values underpinning STEM education in the USA: An analysis of the Next Generation Science Standards. Science Education, 101(2), 278-301. https://doi.org/10.1002/sce.21260

Huff, K. L. (2016). Addressing three common myths about the next generation science-standards. Science Teacher, 83(1), 55-58. https://doi.org/10.2505/4/tst16_083_01_55

Isabelle, A. D. (2017). STEM is elementary: Challenges faced by elementary teachers in the era of the next generation science standards, The Educational Forum, 81(1), 83-91. https://doi.org/10.1080/00131725.2016.1242678

Jo Ellen, R., Herrmann-Abell, C. F., \& Koppal, M. (2017). Designing for the next generation science standards: Educative curriculum materials and measures of teacher Knowledge. Journal of Science Teacher Education, 28(1), 111-141.

Kastberg, D., Chan, J. Y., \& Murray, G. (2016). Performance of US 15-year-old students in science, reading, and mathematics literacy in an international context: First look at PISA 2015. NCES 2017-048. National Center for Education Statistics. Retrieved from https://nces.ed.gov/pubs2017/2017048.pdf

Klein, J. I., Rice, C., \& Levy, J. (2012). Education reform and national security. Independent Task Force Report No. 68. Council on Foreign Relations Press. Retrieved from

https://www.cfr.org/sites/default/files/report_pdf/TFR68_Education_National_Security.pdf

Lee, H. J., Messom, C., \& Yau, K. A. (2013). Can electronic textbooks be part of K-12 education? Challenges, technological solutions and open issues. Turkish Online Journal of Educational Technology, 12(1), 33-44.

Liu, M., Navarrete, C. C., \& Wivagg, J. (2014). Potentials of mobile technology for K-12 education: An investigation of iPod touch use for English language learners in the United States. Educational Technology \& Society, 17(2), 115126.

McComas, W. F., \& Nouri, N. (2016). The nature of science and the next generation science standards: Analysis and critique. Journal of Science Teacher Education, 27(5), 555-576. https://doi.org/10.1007/s10972-016-9474-3

Micheal, R. D., Webster C., Patterson, D., Laguna, P., \& Sherman, C. (2016). Standards-based assessment, grading, and professional development of California middle school physical education teachers. Journal of Teaching in Physical Education, 35(3), 277-283. https://doi.org/10.1123/jtpe.2015-0162

Moreno, N. P. (1999). K-12 science education reform-a primer for scientists. BioScience, 49(7), 569-576. https://doi.org/10.2307/1313477

National Academies of Sciences, Engineering, and Medicine. (2015). Science Teachers Learning: Enhancing Opportunities, Creating Supportive Contexts. Committee on Strengthening Science Education through a Teacher Learning Continuum. Board on Science Education and Teacher Advisory Council, Division of Behavioral and Social Science and Education. Washington, DC: The National Academies Press.

National Research Council, (2012). A framework for K-12 science education: Practices, crosscutting concepts, and core ideas. Washington, DC: The National Academies Press.

National Research Council. (2014). Developing Assessments for the Next Generation Science Standards. Committee on Developing Assessments of Science Proficiency in K-12. Board on Testing and Assessment and Board on Science Education, J.W. Pellegrino, M.R. Wilson, J.A. Koenig, and A.S. Beatty, Editors. Division of Behavioral and Social Sciences and Education. Washington, DC: The National Academies Press.

National Science Teachers Association (NSTA) (2016). NSTA position statement: The national science teachers' association. 
National Science Teachers Association (NSTA). (2016). About the next generation science standard. Retrieved from http://ngss.nsta.org/About.aspx

NGSS Lead States (2013). Next Generation Science Standards: For States, By States. Washington, DC: The National Academies Press.

Penuel, W. R., Harris, C. J., \& DeBarger, H. A. (2015). Implementing the next generation science standards. Phi Delta Kappan, 96(6), 45-49. https://doi.org/10.1177/0031721715575299

Roberts-Mahoney, H., Means A. J., Mark J., \& Garrison, M. J. (2016). Netflixing human capital development: personalized learning technology and the corporatization of K-12 education, Journal of Education Policy, 31(4), 405-420. https://doi.org/10.1080/02680939.2015.1132774

Schmidt, W. H., Wang, H. A., \& McKnight C. C. (2005). Curriculum coherence: An examination of US mathematics and science content standards from an international perspective. Journal of Curriculum Studies, 37(5), 525-559. https://doi.org/10.1080/0022027042000294682

Selwyn, N. (2015). Minding our language: Why education and technology is full of bullshit ....and what might be done about it. Learning, Media \& Technology, 1-8. https://doi.org/10.1080/17439884.2015.1012523

Sibert, S., \& Rieg, S. (2016), Early childhood special education pre-service teachers: Perceived self-confidence in traditional and professional development school field placements. National Teacher Education Journal, 9(2), 47-56.

Steingberg, M. (2011). Working Together to Increase STEM Interest: Communal Experience and Its Effect on the Malleability of STEM Beliefs and Attitudes (Unpublished master's thesis). Miami University, Oxford.

Stout, J. G., Grunberg, V. A., \& Ito, T. A. (2016). Gender roles and stereotypes about science careers help explain women and men's science pursuits. Sex Roles, 75, 490-499. https://doi.org/10.1007/s11199-016-0647-5

Tondeur, J., Forkosh-Baruch, A., Prestridge, S., Albion, P., \& Edirisinghe, S. (2016). Responding to challenges in teacher professional development for ICT integration in education. Educational Technology \& Society, 19(3), 110-120.

U.S. Department of Education (2015). National Assessment of Educational Progress (NAEP), various years, 1990-2013 Mathematics and Reading Assessments. Institute of Education Sciences, National Center for Education Statistics.

Wang, M., \& Degol, J. (2013). Motivational pathways to STEM career choices: Using expectancy-value perspective to understand individual and gender differences in STEM fields. Developmental Review, 33(4), 304-340. https://doi.org/10.1016/j.dr.2013.08.001

Wysession, M. (2015). Next generation science standards: Preparing students for careers in energy-related fields. The Leading Edge, 34(10) 1166-1176. https://doi.org/10.1190/tle34101166.1

\section{Copyrights}

Copyright for this article is retained by the author(s), with first publication rights granted to the journal.

This is an open-access article distributed under the terms and conditions of the Creative Commons Attribution license which permits unrestricted use, distribution, and reproduction in any medium, provided the original work is properly cited. 